\title{
Arqueología de la Quebrada de Las Cuevas (Salta, Argentina) treinta años después: Excavaciones en el sitio formativo Las Cuevas V
}

\author{
María Eugenia De Feo
}

División de Arqueología, Museo de La Plata, Facultad de Ciencias Naturales y

Arqueología

Museo, Universidad Nacional de La Plata.

E-mail: eugeniadefeo@yahoo.com.ar

\begin{abstract}
Resumen
Esta contribución tiene como objetivo presentar los avances realizados a partir de las investigaciones arqueológicas recientemente desarrolladas en el sitio Las Cuevas V (Quebrada de Las Cuevas, Salta, Argentina), Ias cuales reactivaron el estudio de las ocupaciones formativas luego de más de tres décadas de los últimos trabajos en el área. Se ofrece una presentación general de sitio, su emplazamiento y arquitectura, con especial referencia a la Estructura 1. Asimismo, se presentan los resultados del análisis de los conjuntos materiales recuperados de su excavación, los cuales comprenden fragmentos cerámicos, instrumentos y desechos líticos y restos arqueofaunísticos. Finalmente, se discuten aspectos vinculados con la cronología de la ocupación, la funcionalidad del sitio y la estructura excavada y las implicancias derivadas de tales evidencias en las estrategias de organización y uso del espacio en el área durante el Formativo Temprano.
\end{abstract}

Palabras claves: Las Cuevas V; Formativo; cronología; funcionalidad; espacio.

Archaeology of the Quebrada de las Cuevas (Salta, Argentina) thirty years later: Excavations at the Formative site Las Cuevas V

\begin{abstract}
This contribution presents progress of recent archaeological research carried out at Las Cuevas V site (Quebrada de Las Cuevas, Salta, Argentina), thus reopening previous studies on Formative occupations in the same area. An overview of the site is presented, as well as its location and architecture, particularly referred to Structure 1. Also the results of analysis on material assemblages retrieved from the latter archeological dig are presented. They include pottery sherds, lithic tools and faunal remains. Finally, issues related to chronology, site function, the excavated structure and the organization and strategies of space use in the area during the Formative Period are discussed.
\end{abstract}

Keywords: Las Cuevas V; Formative; chronology; functionality; space.

En 2002, transcurridos más de treinta años de los últimos trabajos arqueológicos llevados a cabo por la División de Antropología del Museo de La Plata bajo la dirección del Dr. Eduardo Cigliano en la Quebrada del Toro y tributarias, reiniciamos las investigaciones en el área con el objetivo de profundizar y rever los resultados alcanzados décadas atrás, en particular aquellos vinculados con las ocupaciones formativas.

Aquellas investigaciones permitieron la definición de un Período Formativo Inferior ubicado entre el 600 a.C y el 400 d.C, identificado en varios sitios arqueológicos, de los cuales tres fueron excavados sistemáticamente: Las Cuevas, Cerro el Dique y Potrero Grande (Cigliano et al. 1976; Raffino 1977; Raffino y Togo 1970). Los restantes sitios (La Mina, Las Capillas y La Encrucijada) fueron hallazgos aislados, reportados por habitantes de la zona. A partir de estas evidencias se propuso un modelo de aldeas agropastoriles, económicamente autosuficientes, localizadas preferentemente en fondos de valle y en asociación con campos agrícolas, estepas de pastoreo y cotos de caza (Raffino 1977). Los sitios comparten, una serie de rasgos arquitectónicos y patrones cerámicos comunes, tales como la planta circular de tipo semisubterráneo y la alfarería gris monocroma, tricolor e incisa.

Una parte importante de nuestras investigaciones se orientó entonces, a la ubicación y registro de nuevas instalaciones. Como resultado de las tareas de prospección se localizaron alrededor de veinte nuevas instalaciones no documentadas hasta la fecha, entre las que se halla el sitio Las Cuevas V, motivo de esta publicación.

Los trabajos consistieron en el levantamiento de un plano de sitio, la recolección superficial de materiales por

Recibido 30-05-2011. Recibido con correcciones 31-10-2011. Aceptado 21-11-2011 
estructura y la excavación sistemática de cuatro recintos. En esta oportunidad se brinda, junto a una caracterización general del sitio, los resultados de los análisis de los contextos recuperados en la Estructura 1 (LCV-Est1).

Dichos resultados son apropiados para discutir la cronología y funcionalidad del sitio y la estructura analizada, y al mismo tiempo, permiten someter a evaluación ciertos conceptos y modelos tradicionalmente instalados respecto de la forma en que las comunidades formativas locales hicieron uso del espacio.

\section{El Sitio}

Las Cuevas V se localiza en la Quebrada de Las Cuevas, tributaria de la del Toro en su porción meridional, a unos $150 \mathrm{~m}$ de la margen izquierda del río homónimo $\left(24^{\circ} 21^{\prime} 23^{\prime \prime}\right.$ lat S, 66 $6^{\circ} 12^{\prime \prime}$ long O) y a $500 \mathrm{~m}$ del sitio conocido Las Cuevas I'. Se emplaza sobre una terraza fluvial, a $3321 \mathrm{msnm}$ (Figura 1). Actualmente el sitio está dividido en dos sectores por un camino que une la localidad de Las Cuevas con la porción más septentrional de la Quebrada del Toro.

Las Cuevas V ocupa una superficie de aproximadamente $13.000 \mathrm{~m}^{2}$, en donde se contabilizan un total de 34 estructuras, mayormente de forma circular, asociadas a otras cuadrangulares de grandes dimensiones Las primeras son de tipo semisubterráneo, y sus diámetros oscilan entre 1 y $15 \mathrm{~m}$. Predominan las de tamaño pequeño, de entre 1 y $2 \mathrm{~m}$ de diámetro $(n=12)$, seguidas por las medianas, de entre 3 y $7 \mathrm{~m}$ de diámetro $(n=9)$ y las grandes, de diámetros superiores a los $7 m(n=3)$. En algunos casos, las estructuras circulares grandes se hallan adosadas a otras de igual forma y menor tamaño. Las estructuras cuadrangulares son escasas, una de ellas es de tamaño grande (superior a los $100 \mathrm{~m}^{2}$ ) y las dos restantes de tamaño más reducido (menores a los $100 \mathrm{~m}^{2}$ ) y sólo en el caso de las más pequeñas se ha verificado el carácter semisubterráneo de los recintos. En el extremo norte se destaca un extenso muro que circunscribe parcialmente un amplio espacio sin estructuras. Se registran además, muros aislados y varios recintos cuya forma no fue posible de definir como consecuencia de su deterioro o de la sedimentación del área (Tabla 1).

En la mayoría de los casos observados se conservan exclusivamente los cimientos, constituidos por paredes dobles y en menor proporción, de tipo simple, de piedra. Las primeras se encuentran rellenas de barro y ripio, y pueden presentar o no argamasa. Los espesores son también regulares, con un ancho mínimo de $40 \mathrm{~cm}$ y uno máximo de $80 \mathrm{~cm}$. Las rocas más utilizadas son los esquistos, ignimbritas y basaltos de coloración gris, negra o rojo oscuro y, de tratarse de granitos o areniscas, casi siempre son grises o blanquecinos. Esta selectividad no sólo comprende el tipo y color de la roca sino también su

\footnotetext{
1 Utilizaremos la denominación Las Cuevas I para referirnos al sitio previamente conocido Las Cuevas.
}

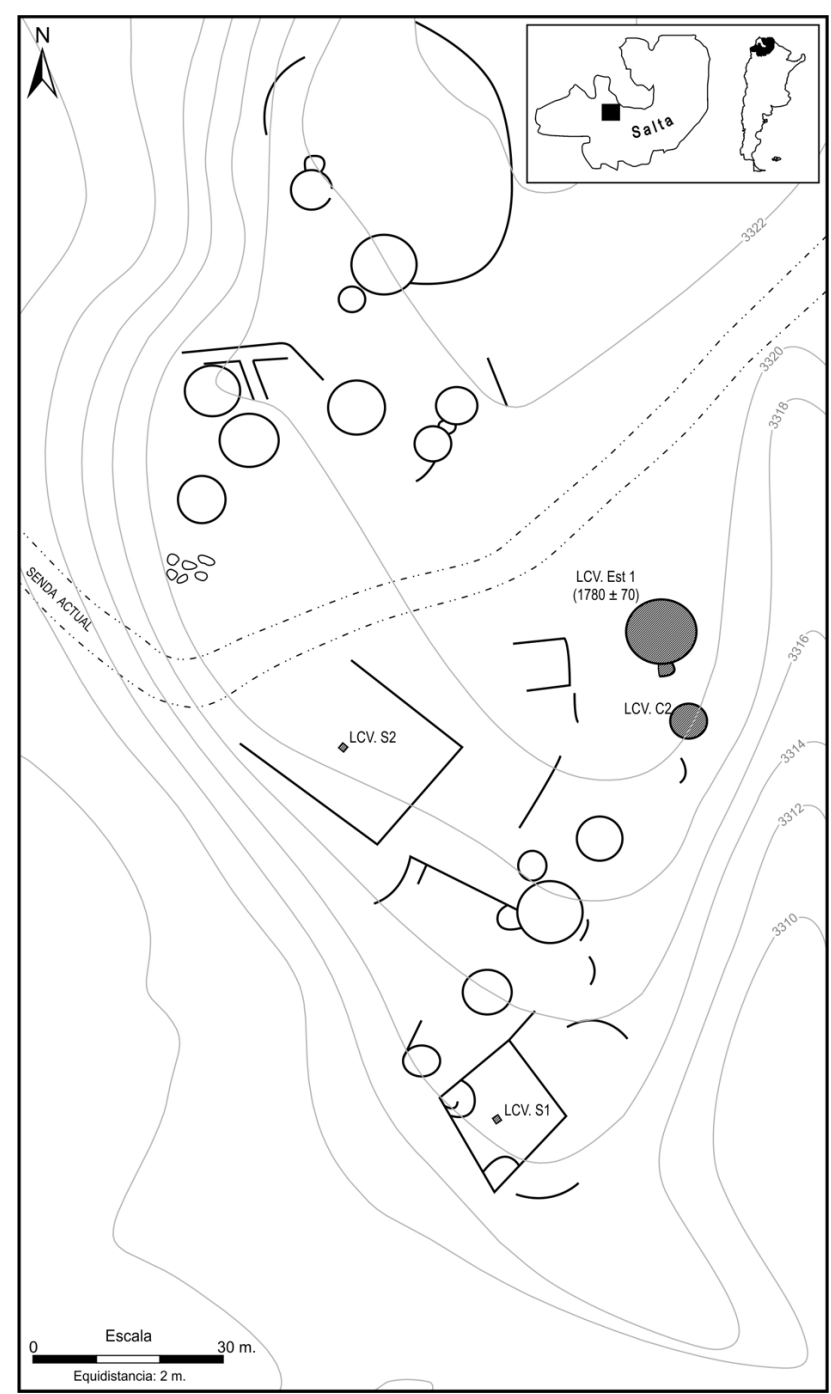

Figura 1. Plano del sitio Las Cuevas V.

Figure 1. Map of Las Cuevas V site.

forma. Se han utilizado bloques de caras más bien planas, dispuestos con su eje mayor vertical. Las hileras superiores en cambio, se levantaron con bloques de formas más irregulares y de menores dimensiones. Las piedras de la hilada inferior suelen medir entre 25 y $70 \mathrm{~cm}$ de altura y en el caso de la Estructura 1, estas se presentan clavadas por debajo del piso de ocupación.

\section{La excavación de la Estructura 1}

La Estructura 1 es circular grande, de 9 m de diámetro y es de tipo semisubterráneo con paredes dobles de piedra (Figura 2). Fue excavada íntegramente, por cuadrantes (N, S, E y O), dentro de los cuales se segregaron varios microsectores. Asimismo, se llevó a cabo el registro tridimensional de los rasgos más destacados.

Posee un vano de acceso delimitado por dos pequeñas jambas, con un escalón de piedras, de $80 \mathrm{~cm}$ de ancho. En el área de la puerta, a manera de deflector, el primero 


\begin{tabular}{|c|c|c|c|c|c|c|c|c|c|}
\hline Tipo & & $\begin{array}{l}\text { Circ. Pequeña } \\
\quad(<3 \mathrm{M})\end{array}$ & $\begin{array}{l}\text { Circ. Mediana } \\
\text { (3 A } 7 \text { M) }\end{array}$ & $\begin{array}{l}\text { Circ. Grande } \\
\qquad(>7 \mathrm{M})\end{array}$ & $\begin{array}{l}\text { Cuadr. Grande } \\
\qquad\left(<100 \mathrm{M}^{2}\right)\end{array}$ & $\begin{array}{c}\text { Cuadr. Menor } \\
\left(>100 \mathrm{M}^{2}\right)\end{array}$ & $\begin{array}{l}\text { Muros } \\
\text { Aislados }\end{array}$ & Indet. & Total \\
\hline \multirow{2}{*}{ LC V } & $\mathrm{N}$ & 12 & 9 & 3 & 1 & 2 & 1 & 4 & 32 \\
\hline & $\%$ & 37,50 & 28,13 & 9,38 & 3,13 & 6,25 & 3,13 & 12,50 & 100 \\
\hline
\end{tabular}

Tabla 1. Número y porcentaje de estructuras según forma y tamaño.

Table 1. Number and frequency of structures sorted by shape and size.

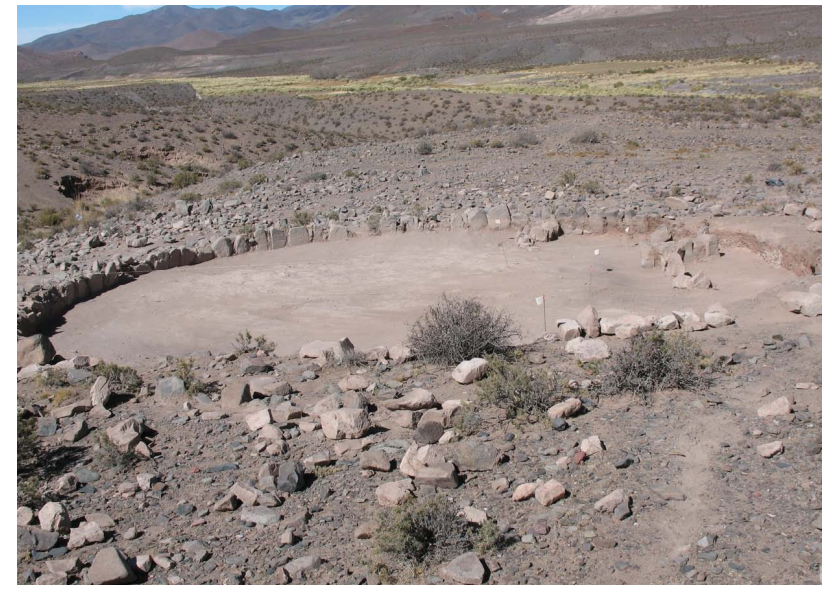

Figura 2. Excavación de la Estructura 1 del sitio Las Cuevas V.

Figure 2. Las Cuevas V, Structure 1 excavation.

documentado para el formativo temprano en el área, se halla otra pequeña estructura semiabierta construida a nivel. Es subcuadrangular, de $2 \times 2 \mathrm{~m}$ y está formada por una pared doble, perpendicular a la Estructura 1 y otra simple, paralela. Los bloques son similares a los observados en la mayor: esquistos, basalto y granitos, aunque más pequeños e irregulares.

Su excavación permitió identificar un piso de ocupación consolidado de unos $10 \mathrm{~cm}$ de potencia, ubicado a los $40 \mathrm{~cm}$ de profundidad desde el nivel actual del suelo. El mismo posee una leve inclinación en el sentido de la pendiente natural del terreno, un desnivel de alrededor de $20 \mathrm{~cm}$ y es distinguible estratigráficamente por su compactación y color blanquecino. Sobre su superficie se registraron las mayores concentraciones de material y es el nivel de apoyo de elementos arquitectónicos secundarios como paredes internas, pozos de postes y fogones (Figura 3).

Hacia el centro de la estructura se registró un área de combustión de forma irregular, de $1 \mathrm{~m}$ de largo por 0,40 $\mathrm{m}$ de ancho, y 0,20 $\mathrm{m}$ de profundidad. También se hallaron otros tres sectores de combustión similares, cercanos a las paredes internas del recinto. Son pequeños, de alrededor de 0,30 $\mathrm{m}$ de diámetro y de escasa profundidad. Asociado a uno de ellos se halló una vasija con restos de hollín. Ninguna de estas estructuras de combustión fue demarcada por piedras; los únicos elementos identificatorios son la presencia de arcilla o

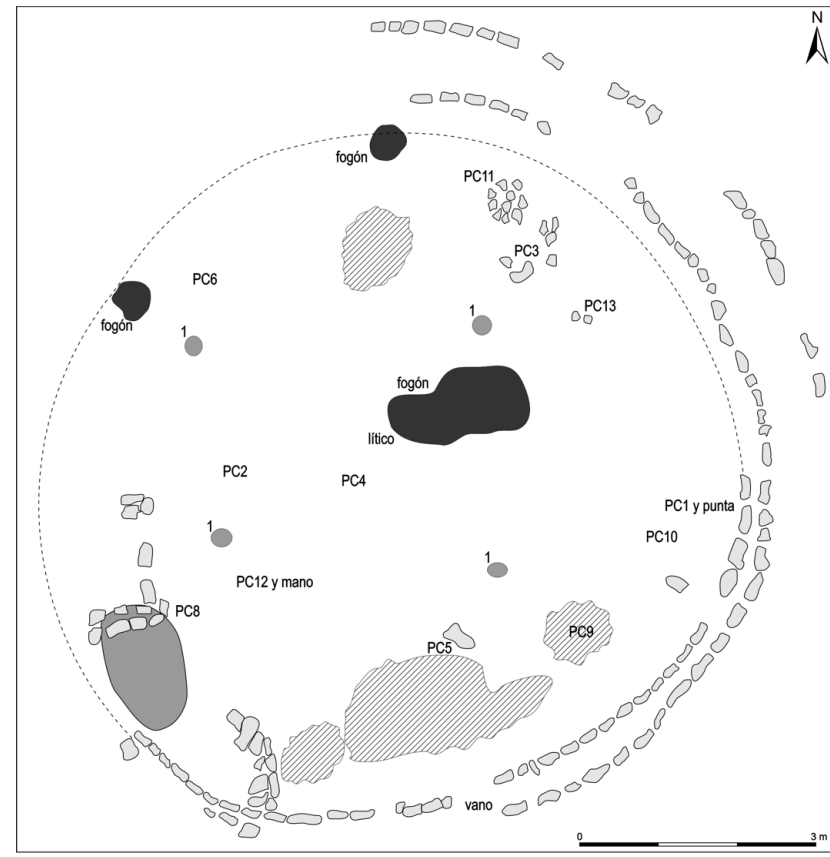

Figura 3. Planta de excavación del piso de ocupación de Estructura 1 del sitio Las Cuevas V. Referencias: PC= pieza cerámica; $1=$ pozos de poste; áreas en rallado corresponden a sectores de concentración ósea y en gris claro al sector de descarte o basural.

Figure3. Map of Las Cuevas V. Structure 1 excavation. References: PC: pottery; 1: post hole; stripped areas shows bone concentrations; in light grey the discard area.

tierra quemada, cenizas, carbones y alfarería con restos de hollín.

La estructura posee además, una división interna en el ángulo sudoeste, definida por dos paredes dobles de piedras, debajo de las cuales se registró un área de descarte donde predominan los restos óseos, principalmente de camélidos. Una cuestión relevante a la dinámica de ocupación de la estructura, lo constituye el hecho de que este basural en determinado momento fue clausurado y sobre él se construyó una pared interna que compartimenta el recinto, de las mismas características y materias primas utilizadas en el perímetro del recinto mayor.

Se hallaron además cuatro marcas de poste de forma oval o subcircular, con restos de madera en su interior. Los mismos se ubican uno por cada cuadrante, equidistantes entre sí. Tienen alrededor de $20 \mathrm{~cm}$ de diámetro y 50 $\mathrm{cm}$ de profundidad. En cada una de las oquedades se 


\begin{tabular}{|c|c|c|c|c|c|c|}
\hline Procedencia & Autor & Material & $\begin{array}{c}\text { Edad } \\
\text { C14 convencional }\end{array}$ & $\begin{array}{l}\text { Edad calibrada } \\
1 \\
\end{array}$ & $\begin{array}{l}\text { Edad calibrada } \\
2 \\
\end{array}$ & Código \\
\hline $\begin{array}{c}\text { LCI } \\
\text { Montículo S } \\
\text { Basural }\end{array}$ & $\begin{array}{c}\text { Cigliano et al } \\
1976\end{array}$ & $\begin{array}{l}\text { Carbón } \\
\text { vegetal }\end{array}$ & $2485 \pm 60$ AP & 743 - 405 a.c & 761 - 399a.C & GRN 5852 \\
\hline $\begin{array}{c}\text { LCI } \\
\text { Montículo E } \\
\text { Basural }\end{array}$ & $\begin{array}{c}\text { Cigliano et al } \\
1976\end{array}$ & $\begin{array}{l}\text { Carbón } \\
\text { vegetal }\end{array}$ & $2150 \pm 80$ AP & 342 a.C - 0 d.C & 361 a.C - 59 d.C & CSIC 121 \\
\hline $\begin{array}{c}\text { LCl } \\
\text { Montículo N } \\
\text { Recinto } 5\end{array}$ & $\begin{array}{c}\text { Cigliano et al } \\
1976\end{array}$ & $\begin{array}{l}\text { Carbón } \\
\text { vegetal }\end{array}$ & $2070 \pm 50$ AP & 89 AC - 57 d.C & 172 a.C -85 d.C & CSIC 122 \\
\hline $\begin{array}{c}\text { LC V } \\
\text { Fogón } \\
\text { Estructura } 1\end{array}$ & De Feo M.E & $\begin{array}{l}\text { Carbón } \\
\text { vegetal }\end{array}$ & $1780 \pm 70 \mathrm{AP}$ & $239-404$ d.C & $128-531$ d.C & LP-1893 \\
\hline $\begin{array}{c}\text { LCI } \\
\text { Montículo S } \\
\text { Basural }\end{array}$ & Raffino 1977 & $\begin{array}{l}\text { Carbón } \\
\text { vegetal }\end{array}$ & $1710 \pm 50 \mathrm{AP}$ & $263-527$ d.C & $256-537$ d.C & CSIC 126 \\
\hline
\end{tabular}

Tabla 2. Fechados radiocarbónicos disponibles para ocupaciones formativas de la Quebrada de Las Cuevas.

Table 2. Available radiocarbon dates for Quebrada de Las Cueva Formative occupations.

hallaron leños correspondientes a la familia Cactaceae, probablemente Cereus, Trichocereus o Stentsonia², los géneros más utilizados en el norte argentino, por su porte, como material constructivo (Capparelli y Raffino 1997).

La disposición de los postes, la forma circular y el tamaño del recinto sugieren un techado de tipo cónico similar al que se registra etnográficamente para el área de Puna y su borde (Vivante y Palma 1966; De Feo 2010).

Una muestra de carbón vegetal recuperada del fogón principal dio un fechado radiocarbónico de $1780 \pm 70$ años AP (Edad radiocarbónica convencional). En la Tabla 2 se detallan los fechados disponibles para la Quebrada de Las Cuevas que corresponden a ocupaciones formativas, expresados en edad radiocarbónica convencional y calibrados con 1 y 2 sigmas.

\section{El análisis de los materiales}

Los conjuntos materiales que se describen a continuación se asocian al piso de ocupación de la Estructura 1 y consisten básicamente en fragmentos de alfarería, restos óseos, artefactos y desechos líticos. En el análisis se han dejado de lado aquellos provenientes del relleno. En la Figura 3 se detalla la distribución espacial de los rasgos más significativos.

\section{El conjunto cerámico}

Con el objeto de sistematizar la información relacionada con los contextos cerámicos recuperados nos hemos basado en la tipología cerámica propuesta por Cigliano et al. (1976), sobre la cual hemos realizado algunas modificaciones a partir de nueva información obtenida. Lo

\footnotetext{
2 Determinación realizada por las Dras. Aylén Capparelli y Verónica Lema, Museo de La Plata.
}

mismo hemos hecho con los grupos morfológicos, sobre los que hemos agregado algunas categorías.

El conjunto analizado se compone de 519 fragmentos. Predominan en él las cerámicas No Ordinarias por sobre las de tipo Ordinario, representadas respectivamente por un $68 \%(n=356)$ y $22 \%(n=114)$. Mientras que un $10 \%(n=49)$ no pudo ser determinado debido a sus dimensiones reducidas o a mal estado de conservación de su superficie (Figura 4).

El conjunto Ordinario reúne aquellos fragmentos que no presentan ningún tratamiento especial de su superficie, como pulido o decorado. En términos generales las piezas remontadas muestran gran variabilidad en el color y acabado. Por ejemplo, algunas vasijas presentan su superficie alisada, a excepción de la base que se muestra escasamente regularizada, incluso más espesa, posiblemente para lograr una mayor resistencia térmica o mecánica. En otros casos se observa variación en la tonalidad de la superficie de las piezas como consecuencia

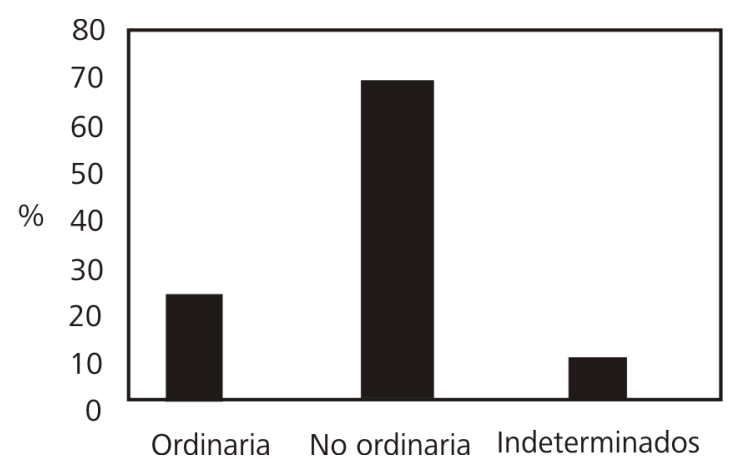

Figura 4. Porcentaje de fragmentos para los grupos de cerámica Ordinaria y No Ordinaria del sitio Las Cuevas V - Estructura $1(n=519)$.

Figure 4. Las Cuevas V, Structure 1 percentage of Ordinary and fine pottery fragements $(n=519)$ 


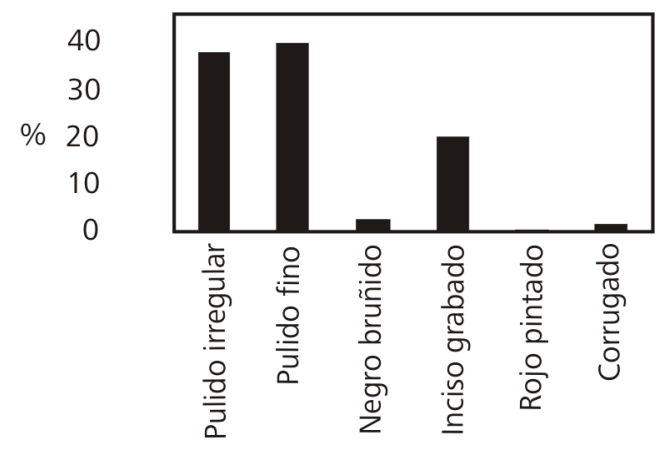

Figura 5. Porcentaje de fragmentos para los tipos de cerámicas No Ordinarias del sitio Las Cuevas V - Estructura $1(n=356)$.

Figure 5. Las Cuevas V, Structure 1 percentage of fine pottery fragments ( $n=356)$.

de su cocción despareja o la exposición posterior al fuego.

En rasgos generales el tipo incluye fragmentos con superficies alisadas en diferente grado, en algunos casos muy escasamente regularizadas o con revoques, las pastas son poco compactas y suelen posee manchas de cocción.

Dentro del conjunto de las cerámicas No Ordinarias un $21,35 \%$ muestra alguna técnica decorativa, mientras que el $78,65 \%$ no ha sido decorado (Figura 5).

El tipo Pulido Fino es el más representado entre las cerámicas No Ordinarias (39,33\%). Se compone de fragmentos que van desde coloraciones ante, pardas, grises a negruzcas, que han recibido un pulimento regular de su superficie externa y/o interna. Corresponden a tiestos de pastas compactas y antiplástico homogéneo.

Le siguen en representación los fragmentos del tipo Pulido Irregular (37,08\%). Poseen un pulido bastante desparejo, superficies con ondulaciones y sectores que no han sido tratados. En ocasiones el pulido se ha realizado sobre un engobe o baño muy fino del mismo color que la pasta. La superficie interna sólo ha sido tratada en piezas abiertas, en las cerradas se muestra simplemente alisada. Las tonalidades van del ante al gris, pasando por el pardo. La pasta es poco porosa, mayormente de tipo reductora, aunque existen fragmentos oxidantes. Se asemeja al tipo 1-2 Gris, Gris Negro o Negro definido por Olivera para Antofagasta de la Sierra (Olivera 1991) y grupos monocromos de Valle Calchaquí (Tarragó 1980). Algunos casos registrados en el relleno de la estructura presentaron pintura postcocción color rojo o amarillo aplicada sobre fragmentos grises o negros, aspecto que también ha sido observado en el tipo Pulido Fino, y que se asemeja a los documentados en otros sitios de ámbitos puneños (Krapovickas 1955; Olivera 1991).

Los fragmentos del tipo Negro Bruñido (2,25\%) muestran una superficie muy brillante, sumamente pulida o bruñida, donde casi no es posible identificar las líneas de pulimento. Se observa en muchos casos la presencia de mica usada como antiplástico. Se trata siempre de tiestos de coloración negra, de pastas reductoras y paredes muy delgadas (entre 3 y $5 \mathrm{~mm}$ ), que suelen descascararse con facilidad permitiendo ver el núcleo de coloración rojiza muy oscura. Este tipo muestra amplias similitudes, técnicas y morfológicas con el tipo Negro Pulido de San Pedro de Atacama, Chile (Munizaga 1963).

La técnica decorativa más frecuente es la Incisa-Grabada, representada en un $19,66 \%$ sobre el total de fragmentos que presentan algún tratamiento. Los trazos son de anchos variables, entre 1 y $3 \mathrm{~mm}$ y las profundidades van de 2 a $4 \mathrm{~mm}$. Estos poseen diferentes variantes, pudiendo ser de tipo irregular $(n=2)$, inciso punteadas $(n=1)$, de surco ancho $(n=30)$ o regulares $(n=37)$. En muchas ocasiones se combina el uso de la técnica de incisión con el grabado o es difícil distinguirlas, por lo cual las hemos reunido en una misma categoría. Los fragmentos son de superficie color gris, parda, ante y negra, muy pulidas externamente e internamente en piezas abiertas. La pasta es compacta, de tipo reductora y en menor porcentaje oxidante. Los motivos incluyen líneas paralelas y oblicuas, incisiones en forma de $X \circ V$, combinadas en algunos casos con motivos puntiformes. Por sus características morfológicas y estilísticas se asemeja a la cerámica de la Tradición San Francisco (Dougherty 1974).

Los fragmentos de tipo Corrugado constituyen el 1,40\% del grupo No Ordinario. Poseen la superficie de color gris a pardo, pulida regularmente, a excepción de la porción corrugada. También muestra diferentes modalidades, como son el ungiculado y el alisado con algún instrumento de superficie relativamente lisa (símil espátula) o de puntas múltiples. El campo decorativo se halla siempre por debajo del borde de las piezas, siguiendo un sentido horizontal y rítmico. También este tipo presenta similitudes con los tipos corrugados propios de la Tradición San Francisco (Dougherty 1974).

Los fragmentos pintados están muy escasamente representados $(0,28 \%)$, en el único caso documentado la pintura es color rojo, aplicada en una capa espesa, la superficie muy pulida y la pasta oxidante (Tipo Rojo Pintado). No se han registrado en la muestra fragmentos del tipo Las Cuevas Tricolor o Vaquerías (Heredia et al. 1974).

En lo referente a la morfología de las piezas, dentro del grupo Ordinario se registran cuencos de contorno compuesto, paredes divergentes y punto angular cercano al borde de tipo vertical y una jarra de tipo calceiforme. Las piezas identificadas para el tipo Pulido Irregular son cuencos de contorno compuesto de paredes divergentes, punto angular en la parte media de la pieza y borde de paredes cóncavas; cuencos de contorno compuesto, 
paredes divergentes punto angular cercano al borde de tipo vertical o levemente invertido; cuencos simples de paredes oblicuas, ollas de morfología no determinable y una pequeña jarrita. Por su parte, en el tipo Pulido Fino las formas presentes son cuencos de contorno compuesto no restringido, de paredes divergentes y punto angular en la parte media de la pieza, de pared superior cóncava; cuencos de contorno compuesto, paredes divergentes y punto angular cercano al borde de tipo vertical o levemente invertido $y$, cuencos de contorno simple y paredes divergentes. También se han registrado para este tipo cerámico ollas de perfil no determinable y jarras como las arriba mencionadas. El grupo de los fragmentos Bruñidos sólo se presenta asociados a cuencos de contorno compuesto, paredes divergentes con punto angular cercano al borde de tipo vertical o levemente invertido. Los cuencos de contorno compuesto como los ya descriptos son característicos del grupo Inciso-Grabado, donde también se registran ollas de morfología no determinable y ollas restringidas de contorno complejo. Finalmente, en el tipo Corrugado sólo se reconocen cuencos de contorno compuesto no restringido, de paredes divergentes y punto angular en la parte media de la pieza, de pared superior cóncava.

A partir de los atributos tecno-morfológicos de los fragmentos pudieron remontarse un total de 13 piezas en distinto grado de integridad. A continuación se ofrece una breve descripción de cada una de ellas, detallando las dimensiones en aquellos casos que fue posible su medición (Figura 6 y 7). En la Figura 3 se señala su ubicación dentro de la estructura excavada.

Pieza 1: Cuenco de contorno compuesto, no restringido, de paredes divergentes, punto angular cercano al borde de paredes verticales. Superficie de color gris, con pulido irregular en la cara externa e interna. Decoración Inciso ancho paralelo regular en el punto angular de su cara externa (Altura total $8,2 \mathrm{~cm}$; diámetro máximo $22 \mathrm{~cm}$; diámetro de la boca $22 \mathrm{~cm}$; diámetro de la base $10 \mathrm{~cm}$ ) (Figura 7b).

Pieza 2: Variante del tipo Calceiforme. Vasija de contorno inflexionado. Cuerpo de paredes fuertemente convexas, medio cuello que culmina en una boca lateral de borde evertido, invertido o directo según el segmento. Sin base definida. Superficie color ante-café alisada. Con evidencias de exposición al fuego (Altura total $36 \mathrm{~cm}$; diámetro máximo $25 \mathrm{~cm}$ ) (Figura 7c).

Pieza 3: Cuenco de contorno simple, no restringido, de paredes divergentes $u$ oblicuas, levemente convexas y borde directo. Superficie del tipo pulido fino en la cara externa e interna, de coloración ante-café (Altura total
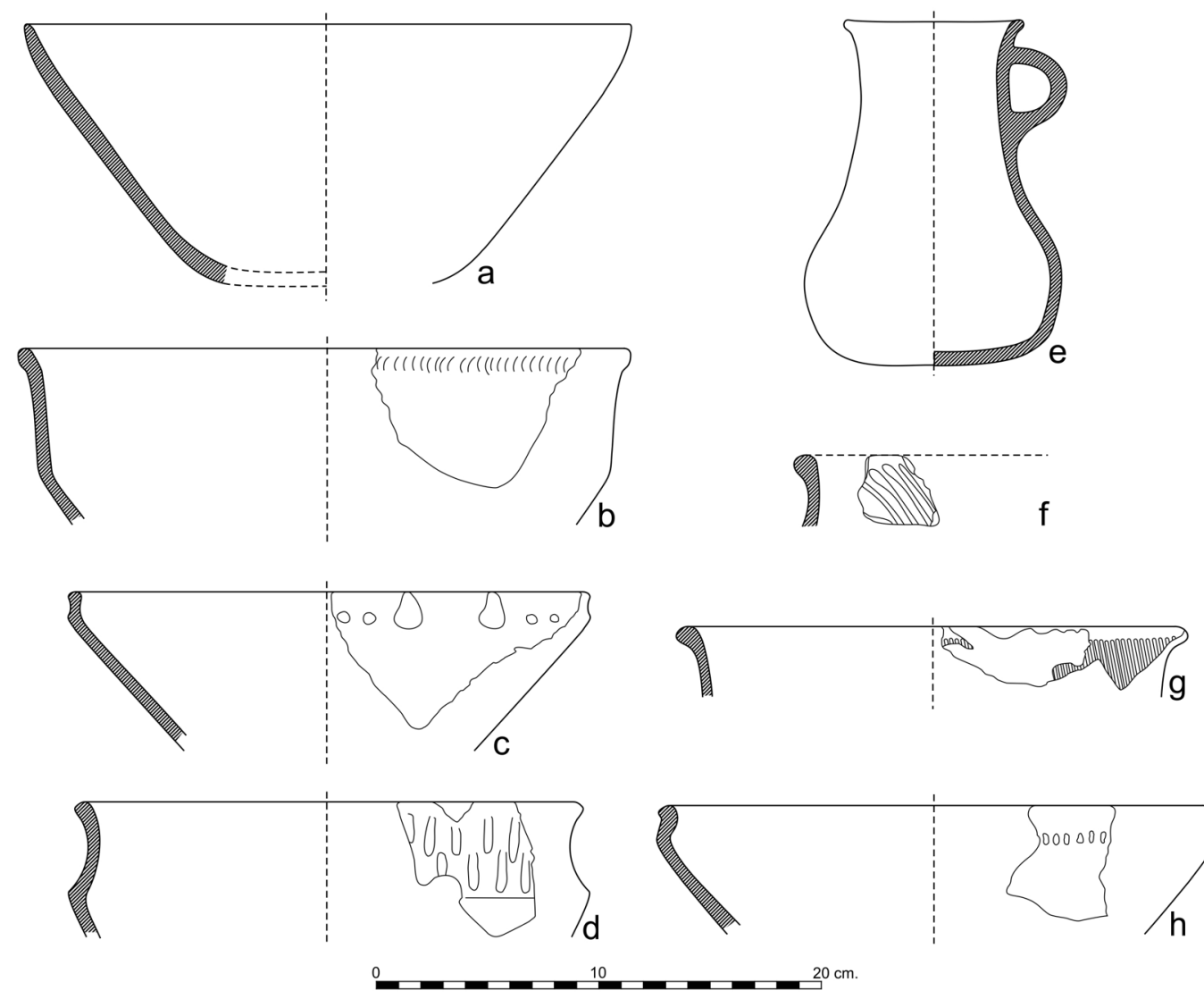

Figura 6. Reconstrucción de piezas cerámicas del sitio Las Cuevas V - Estructura 1.

Figure 6: Las Cuevas V, Structure 1 pottery reconstrution. 

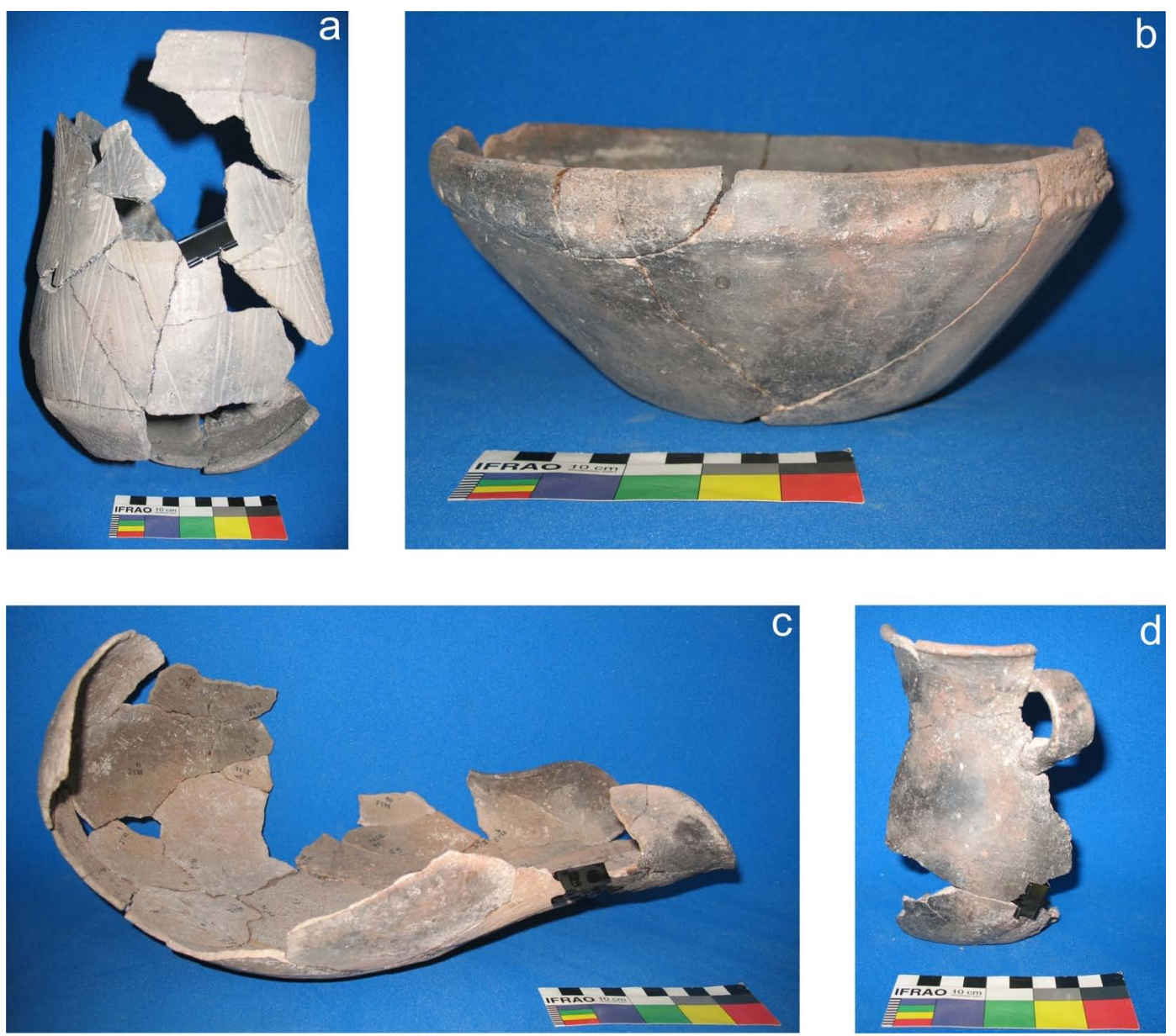

Figura 7. Fotografía de piezas cerámicas parcialmente remontadas del sitio Las Cuevas V-Estructura 1. Arriba derecha pieza 1e izquierda pieza 6 , abajo derecha pieza 5 e izquierda pieza 2.

Figure 7. Refitting of pottery fragments from Las Cuevas V Structure 1.

aproximadamente $12 \mathrm{~cm}$; diámetro máximo $27 \mathrm{~cm}$; diámetro de la boca $27 \mathrm{~cm}$ ) (Figura 6a).

Pieza 4: Cuenco de contorno compuesto, paredes divergentes punto angular cercano al borde de tipo vertical o levemente invertido. Superficie con pulido irregular en la cara externa e interna, de color gris. Presenta manchas de cocción. Tiene un inciso ancho paralelo regular en el punto angular de su cara externa. Dos asas de tipo mamelón en el área del borde (Diámetro de la boca $23 \mathrm{~cm}$ ) (Figura 6c).

Pieza 5: Vasija restringida de contorno inflexionado, el diámetro máximo del cuerpo se halla por debajo de la mitad de la pieza, con cuello alto algo evertido, con base plano plana y asa vertical cuello cuerpo. Superficie con pulido fino en la cara externa e irregular en la interna, de color negro con manchas de cocción color café (Altura total $14 \mathrm{~cm}$; diámetro máximo $13 \mathrm{~cm}$; diámetro de la boca $10 \mathrm{~cm}$; diámetro de la base $9 \mathrm{~cm}$ ) Figura 6 e y $7 \mathrm{~d}$ ).

Pieza 6: Vasija restringida de contorno complejo con un punto angular en el cuerpo coincidente con el diámetro máximo. Cuello levemente evertido, de cuerpo subglobular. Base convexa indiferenciada y borde reforzado mediante aplicación de banda externa. Tratamiento superficial de tipo pulido irregular en la cara externa y alisado en la interna, superficie de color gris. Decoración incisa regular en el área del cuello, motivos en $\vee$ y X (Altura total $30,5 \mathrm{~cm}$; diámetro máximo $20 \mathrm{~cm}$; diámetro de la boca $16 \mathrm{~cm}$; diámetro de la base $5 \mathrm{~cm}$ ) (Figura 7a).

Pieza 8: Cuenco de contorno compuesto, no restringido, con punto angular en la parte media de la pieza. Lados verticales y borde levemente evertido (A2). Tratamiento superficial pulido fino en la cara externa e interna, superficie de color gris. Tiene un inciso ungicular debajo del punto angular de su cara externa (Diámetro de la boca $25 \mathrm{~cm}$ ) (Figura 6b).

Pieza 9: Cuenco de contorno compuesto no restringido de paredes divergentes y punto angular en la parte media de la pieza, pared superior cóncava. Superficie de coloración gris, con pulido fino en la cara externa e interna. Decoración incisa regular por debajo del borde 
(Diámetro de la boca $22 \mathrm{~cm}$ ) (Figura 6g).

Pieza 10: Cuenco de contorno compuesto, paredes divergentes punto angular cercano al borde de tipo vertical o levemente invertido. Pulido en la cara externa alisado en la cara interna, superficie de color ante (Diámetro de la boca $24 \mathrm{~cm}$ ).

Pieza 11: Cuenco de contorno compuesto no restringido de paredes divergentes y punto angular en la parte media de la pieza, pared superior cóncava. Tratamiento superficial pulido fino en la cara interna y externa, superficie de color gris. Decoración incisiones espatulares paralelas poco profundas hasta el punto angular (Diámetro de la boca $22 \mathrm{~cm}$ ) (Figura 6d).

Pieza12: Cuenco de contorno compuesto no restringido de paredes divergentes y punto angular en la parte media de la pieza, pared superior cóncava, con tratamiento de tipo corrugado.

Pieza 13: Cuenco de contorno compuesto no restringido de paredes divergentes y punto angular en la parte media de la pieza, pared superior cóncava. Tratamiento superficial pulido fino en la cara interna y externa, a excepción del sector decorado. Superficie externa de color gris. Decoración digito-espátular en el área debajo del borde (Figura 6f).

En términos generales los tipos cerámicos identificados se corresponden con los ya observados por Cigliano et al. (1976) y Raffino (1977) para el sitio Las Cuevas I. A excepción de algunos tipos morfológicos antes no conocidos como las piezas 2, 5 y 6 , las formas observadas también son las mismas registradas para los diferentes tipos cerámicos tempranos. Como se desprende de las descripciones anteriores, en su gran mayoría se trata de cuencos de superficies pulidas, mayormente con pulido fino y decoración inciso-grabada o corrugada, aunque también se han hallado formas restringidas y de mayor tamaño, como jarras y ollas.

\begin{tabular}{lcc}
\hline Conjunto lítico & $\mathrm{N}$ & $\%$ \\
\hline Artefactos de. Bisel asimétrico & 3 & $1,12 \%$ \\
Artefacto de formatización sumaria & 5 & $1,87 \%$ \\
Cortante & 1 & $0,37 \%$ \\
Fragmento de artefacto no diferen- & 12 & $4,50 \%$ \\
ciado. & 10 & $3,75 \%$ \\
Puntas y preformas de puntas & 1 & $0,37 \%$ \\
Perforador & 222 & $83,15 \%$ \\
Lascas & 13 & $4,87 \%$ \\
Desechos no clasificables. & 267 & $100,00 \%$ \\
Total & & \\
\hline
\end{tabular}

Tabla 3. Número y porcentaje de piezas líticas del sitio Las Cuevas $\mathrm{V}$ - Estructura 1.

Table 3. Number and frequency of lithic items from Las Cuevas $V$, Structure 1.

\section{El conjunto lítico}

En la Estructura 1 también se recuperó abundante material lítico $(n=267)$. Incluye mayormente desechos de talla: lascas, microlascas y desechos no clasificables. Los grupos tipológicos observados entre los instrumentos tallados corresponden en orden decreciente a: fragmentos de artefactos no diferenciados, puntas y preformas de puntas de proyectil, artefactos de formatización sumaria, artefactos de bisel asimétrico, cortantes y perforadores (Tabla 3).

Las puntas de proyectil son el grupo de instrumentos más representado $(n=10)$ y por sus características tecnomorfológicas pueden adscribirse a los siguientes subgrupos: 1) módulo triangular corto, con pedúnculo diferenciado y aletas entrantes y 2) módulo romboidal y pedúnculo diferenciado y aletas entrantes o salientes. Existen además otras puntas de limbo triangular, que por su estado de fragmentación no puede definirse con exactitud su pertenencia a algunos de los subgrupos mencionados. Se ha verificado además un ejemplar de tipo lanceolado (Figura 8).

Los desechos de talla presentan un elevado índice de fractura, (61\%), superior al observado en el grupo de los instrumentos, de alrededor del 50\%. Los tamaños más representados son pequeño y mediano-pequeño. Se observó pátina sólo en un 32\% del total de las piezas. El índice de corteza tanto en instrumentos como desechos de talla es escaso, menor al $20 \%$.

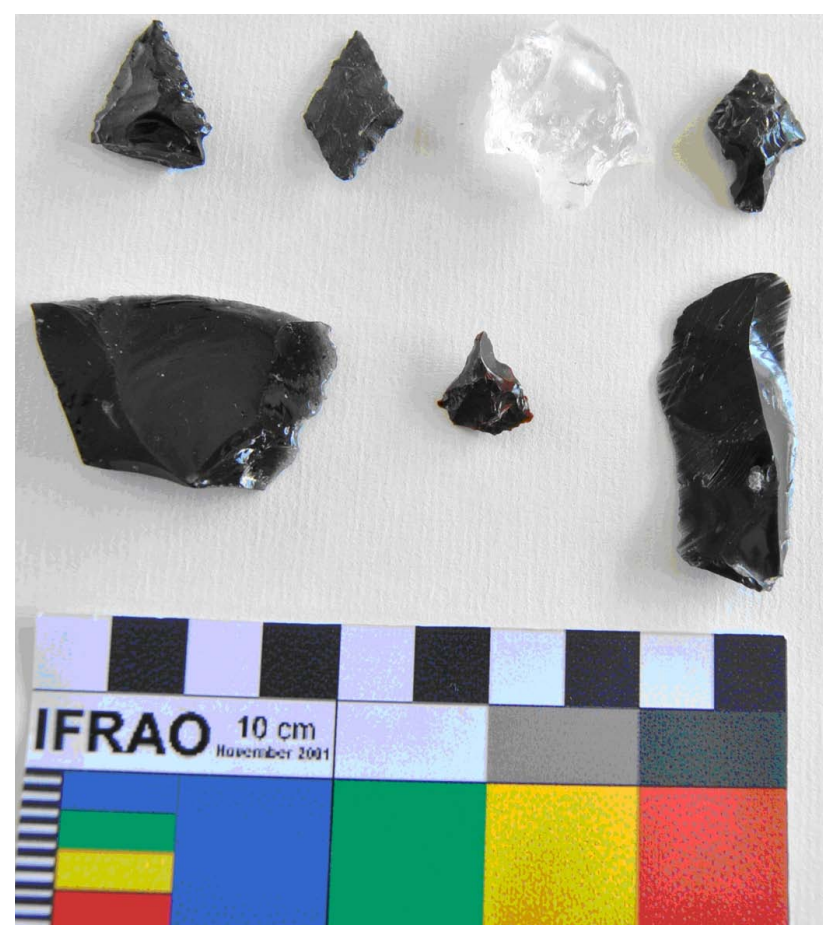

Figura 8. Materiales líticos recuperados en Las Cuevas V - Estructura 1.

Figure 8. Lithic material from Las Cuevas V Structure 1. 
En cuanto a la materia prima (Figuras 9 y 10), domina en el conjunto, tanto en el grupo de los instrumentos como entre los desechos de talla, la obsidiana (90\% y $87 \%$ respectivamente). Le siguen en orden de representatividad los basaltos (6\% y $8 \%$ respectivamente) y en muy escasas proporciones, los esquistos, sílices amorfos, cuarzo y la arenisca silicificada (tanto para los instrumentos como desechos con porcentajes inferiores al 4\%). A excepción de la obsidiana, de origen alóctono $n=356$, y los sílices, de los cuales desconocemos su posible origen, los basaltos, el cuarzo y la arenisca silicificada se hallan disponibles en un radio de distancia no mayor al kilómetro desde el sitio, los dos primeros en forma de guijarros y nódulos dispersos en el terreno o conformando concentraciones relativamente pequeñas y la última como filones en la ladera de los cerros.

La fuente de procedencia de la obsidiana ha sido establecida mediante análisis de Fluorescencia de Rayos $X$ en Zapaleri (en el límite tripartito entre Bolivia, Argentina y Chile) para aquellas de las variedades Negro uniforme, en bandas y manchado y Tocomar (puna de Salta), en el caso de la Gris y Transparente (Álvarez Soncini y De Feo 2010).

Además se hallaron hacia el interior de la Estructura 1 instrumentos líticos manufacturados por pulido y picado. Se trata de un fragmento de mortero confeccionado sobre granito y tres manos de moler, dos circulares planas y una subcircular cilíndrica, todas elaboradas sobre granito.

\section{El conjunto arqueofaunístico}

Para el conjunto arqueofaunístico se estimó un NISP de 838. El taxón más representado corresponde a la familia de los camélidos (Camelidae), presente en un 49,33\%. Le siguen en representación, especímenes correspondientes a mamíferos de difícil asignación (48,11\%). Un 2,07\% pertenece a un ungulado que por tamaño puede ser

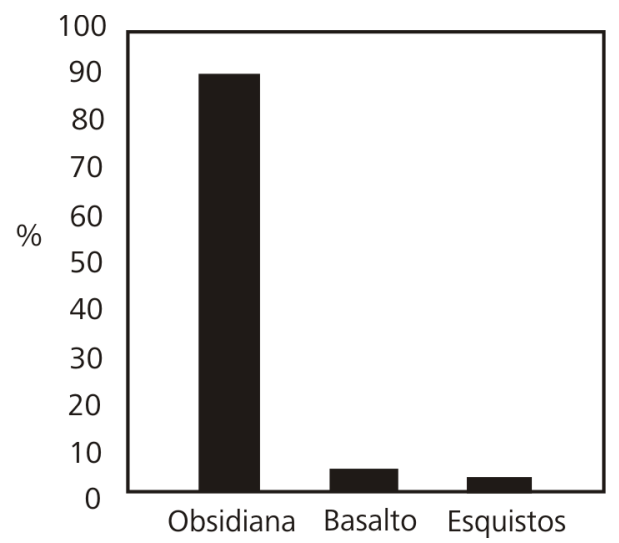

Figura. 9. Porcentaje de materia prima para el grupo de los instrumentos del sitio Las Cuevas V - Estructura $1(n=32)$.

Figure 9. Frequency of raw material for the lithics instruments from Las Cuevas V Structure $1(n=32)$. asignable a camélidos o cérvidos andinos. Los cérvidos (Cervidae indet.) aparecen representados en un 0,12\%, al igual que las aves (Anatidae indet.).

En la Tabla 4 se detalla la frecuencia de los elementos de Camelidae, expresado en NISP, Número Mínimo de Elementos (NME), Número Mínimo de Unidades Anatómicas (MAU) y MAU\%. Como se desprende de su análisis, no todas las partes esqueletarias están representadas en la muestra, no obstante, si bien las unidades anatómicas de mayor rendimiento están bien representadas, como son cuartos traseros y delanteros (fémur, húmero, tibia y costillas), también lo están algunas que carecen de recursos como carne y médula ósea: carpianos, tarsianos, metapodios y falanges, los cuales pudieron ser transportados al sitio de manera articulada.

Con el fin de interpretar mejor el comportamiento del conjunto y de establecer los factores que incidieron en la conformación del conjunto óseo, se efectuaron análisis de correlación no paramétrica entre: 1) la Densidad Mineral Ósea (Elkin 1995) y el MAU \%; 2) el Índice de Carne (Borrero 1990) y el MAU\%; 3) el Índice de Secado (De Nigris y Mengoni 2004) y el MAU\% (Tabla 5).

Los resultados obtenidos no han sido significativos y permiten descartar una preservación diferencial de los huesos, así como también, que la conformación del perfil anatómico esté determinada por su rendimiento económico. En cuanto a la correlación con el índice de secado, se obtuvo un resultado positivo y significativo, lo que daría cuenta que la actividad de charqueado de la carne pudo haberse desarrollado en el sitio con el fin de conservar la carne. La escasez en la muestra de aquellos elementos más aptos para ser deshidratados (costillas, esternebras, vértebras), indicaría que estas partes fueron consumidas fuera de la estructura analizada.

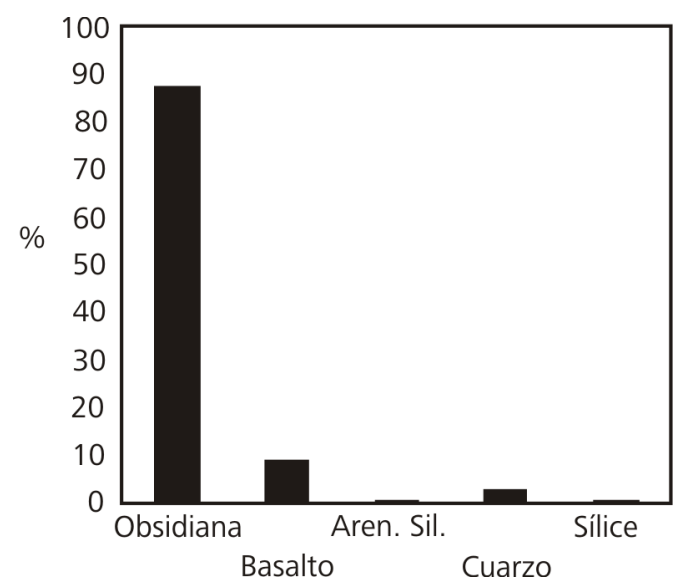

Figura. 10. Porcentaje de materia prima para el grupo de los desechos de talla del sitio Las Cuevas V - Estructura $1(n=235)$.

Figure 10. Frequency of raw material for the lithic debitage from Las Cuevas V Structure 1 ( $n=235)$. 


\begin{tabular}{|c|c|c|c|c|}
\hline Elemento & NISP & NME & MAU & MAU\% \\
\hline Cráneo & 11 & 2 & 2 & 26,7 \\
\hline Hemimandíbula & 6 & 2 & 1 & 13,3 \\
\hline Hioides & 1 & 1 & - & - \\
\hline Atlas & 3 & 2 & 2 & 26,7 \\
\hline Axis & 10 & 4 & 4 & 53,3 \\
\hline V. Cervical & 17 & 8 & 1,6 & 21,3 \\
\hline V. Torácica & 8 & 3 & 0,3 & 3,3 \\
\hline V. Lumbar & 10 & 4 & 0,8 & 10,7 \\
\hline Costilla & 43 & 19 & 0,8 & 10,6 \\
\hline Escápula & 4 & 2 & 1 & 13,3 \\
\hline Húmero px & 1 & 1 & 0,5 & 6,7 \\
\hline Húmero df & 3 & 2 & 1 & 13,3 \\
\hline Húmero ds & 9 & 4 & 2 & 26,7 \\
\hline Radioc px & 8 & 4 & 2 & 26,7 \\
\hline Radioc df & 1 & 1 & 0,5 & 6,7 \\
\hline Radioc ds & 10 & 5 & 2,5 & 33,3 \\
\hline Pelvis & 4 & 2 & 2 & 26,7 \\
\hline Fémur px & 2 & 2 & 1 & 13,3 \\
\hline Fémur df & 2 & 1 & 0,5 & 6,7 \\
\hline Fémur ds & 3 & 2 & 1 & 13,3 \\
\hline Patella & 7 & 3 & 1,5 & 20,0 \\
\hline Tibia px & 4 & 3 & 1,5 & 20,0 \\
\hline Tibia df & 1 & 1 & 0,5 & 6,7 \\
\hline Tibia ds & 12 & 7 & 3,5 & 46,7 \\
\hline Metac px & 3 & 2 & 2 & 26,7 \\
\hline Metatar px & 5 & 3 & 1,5 & 20,0 \\
\hline Metap ds & 16 & 4 & 2 & 26,7 \\
\hline Calcáneo & 33 & 15 & 7,5 & 100,0 \\
\hline Astrágalo & 11 & 10 & 5 & 66,7 \\
\hline Falange 1 & 64 & 35 & 4,4 & 58,3 \\
\hline Falange 2 & 20 & 16 & 2 & 26,7 \\
\hline Falange 3 & 2 & 2 & 0,3 & 3,3 \\
\hline Carpianos & 22 & 20 & 1,4 & 19,0 \\
\hline Tarsianos & 19 & 18 & 1,8 & 24,0 \\
\hline
\end{tabular}

Tabla 4. Conjunto arqueofaunístico de Camelidae del sitio Las Cuevas $\checkmark$ - Estructura 1.

Table 4. Las Cuevas V, Structure 1 Camelid bones assemblage.

El análisis tafonómico del conjunto óseo determinó que el $54,4 \%$ de la muestra posee un grado de meteorización 2 según la modificación de Todd (1987) a la escala de Berehsmeyer; un $32,7 \%$ al grado 3 , un $12,4 \%$ al 4 y un porcentaje menor al $1 \%$ mostró un grado 5 , no existiendo especímenes que puedan ser adjudicados al grado 1. Los valores observados señalan un tiempo relativamente largo de exposición antes del entierro de los restos faunísticos.

La meteorización, sumada a la alta incidencia de raíces -el 83\% de los especímenes tiene rastros de su acciónprobablemente influyó en la fragmentación y deterioro del conjunto arquefaunístico, y al mismo tiempo pueden

\begin{tabular}{lcc}
\hline Marco de referencia & $r_{s}$ & $p$ \\
\hline DO (Elkin 1995) & 0,096 & $0,583>0,05$ \\
IC (Borrero 1990) & $-0,172$ & $0,364>0,05$ \\
$\begin{array}{l}\text { ISC (De Nigris y Mengoni Goñalons } \\
\text { 2004) }\end{array}$ & 0,67 & $0,005<0,05$ \\
\hline
\end{tabular}

Tabla 5. Resultados de los análisis de correlación no paramétrica del sitio Las Cuevas V - Estructura 1.

Table 5. Non parametric correlation results for Las Cuevas V, Structure 1.

estar dificultando la apreciación de otro tipo de marcas. Otras variables registradas han sido la presencia de manchas de manganeso, carbonato y salitre, factores que actuaron sobre el $23,6 \%, 57,4 \%$ y $4 \%$ de los huesos, respectivamente. La depositación química, especialmente la carbonática, alteró notablemente las superficies corticales.

Las marcas producidas por roedores y carnívoros son muy escasas, y afectan sólo al $1 \%$ de la muestra. Las evidencias de origen antrópico están representadas en frecuencias muy bajas, siendo 17 los especímenes que muestran marcas de corte y/o negativos de impacto, estos últimos asociados a fracturas frescas de tipo helicoidal y longitudinal. Su concentración mayoritaria en apófisis vertebrales, costillas y diáfisis de huesos largos, estaría asociada a actividades de desarticulación y descarne. La ausencia casi total de termoalteración $(99,4 \%$ de los especímenes no presenta signos de exposición al fuego), implicaría que el asado de la carne no fue la técnica de cocción predominante y que otras técnicas de cocción pudieron haberse llevado a cabo, como por ejemplo el hervido de los huesos, tal como sugiere Izeta (2004) para contextos tempranos de sur de los Valles Calchaquíes.

\section{Otros hallazgos}

Otros elementos destacados que fueron hallados en el piso de ocupación fueron una placa de mica semejante a la registrada en la Tumba 3 del sitio Las Cuevas I (Raffino 1977), concreciones de pigmentos amarillos y rojos, arcilla y una espátula metálica. Con respecto a esta última, los análisis de microscopía de barrido EDAX arrojaron una composición exclusivamente de cobre. El mismo estudio permitió determinar que el pigmento rojo corresponde a óxidos de Fe con contenidos de Si y Mg, idénticos a los documentados en fragmentos del Tipo Rojo Pintado y otros tipos cerámicos pintados (Vaquerías o Tricolor, Bicolor) de sitios contemporáneos.

\section{Consideraciones generales}

La información desarrollada hasta aquí nos permite discutir aspectos vinculados a la cronología de las ocupaciones tempranas en el área y la funcionalidad del 
sitio y en particular de la estructura cuyos materiales han sido analizados. Asimismo, tiene importantes implicancias sobe los modelos que han sido planteados en el pasado respecto de las formas de uso y organización del espacio en comunidades aldeanas formativas del área.

\section{Cronología}

Los fechados radiocarbónicos con los que contábamos al inicio de nuestras investigaciones para la Quebrada de Las Cuevas provenían exclusivamente del sitio Las Cuevas I. La recalibración de dichos fechados mediante el programa Calib. 5.1.0 para el Hemisferio Sur (Stuiver y Reimer 1986) permite hablar de un rango de ocupación para el sitio de entre 700 a.C y el 500 d.C. Por su parte, el fechado obtenido recientemente para Las Cuevas $\mathrm{V}$ de 239 - 404 d.C (calibrado 1 sigma) señala la relativa contemporaneidad entre ambos sitios, al menos durante parte de sus ocupaciones.

La presencia de alfarería correspondiente al grupo gris monócromo y aquella Inciso-Grabada de similitudes con la tradición San Francisco de las Selvas Septentrionales, reafirman la ubicación cronológica de Las Cuevas $\mathrm{V}$ durante el Período Formativo Temprano o Inferior (700 a.C- 400 d.C)

La cerámica Corrugada o Inciso-grabada registrada tanto en recolecciones de superficie como en las excavaciones en la Estructura 1 de Las Cuevas V, no ha sido documentada en los componentes inferiores de Las Cuevas I, motivo por el cual se la ha considerado propia de una segunda y tercera fase de ocupación de este último, datadas en 342 a.C-57 d.C y 350-527 d.C (calibrado 1 sigma) respectivamente y, caracterizadas por la aparición de nuevas modalidades decorativas en la alfarería (Cigliano et al. 1976). Estas modalidades también son propias de los sitios Cerro El Dique y Potrero Grande, ubicados en la porción septentrional de la Quebrada del Toro, que también presentan fechados que datan su ocupación como posterior a la de Las Cuevas I (349 - 532 d.C y 263 - 527 d.C ambos calibrados, 1 sigma, para el primero y segundo sitio respectivamente).

Además del carácter más temprano de Las Cuevas I, la evidencia también parece indicar que este sitio no fue abandonado una vez establecido Las Cuevas V, dado que el fechado obtenido para los niveles superiores del Montículo Sur del primero de ellos es posterior al arrojado para la ocupación de la Estructura 1.

Las excavaciones llevadas a cabo en Las Cuevas I, también en el marco de esta investigación, nos han permitido establecer que los sectores intermonticulares también fueron ocupados y que la superposición de elementos arquitectónicos que caracteriza al sitio sólo parece estar presente en los sectores monticulares. Aunque desconocemos aún la cronología de las ocupaciones fuera de los montículos. Si fueran posteriores, esto estaría indicando la necesidad de ocupar nuevos sectores, posiblemente como consecuencia del crecimiento demográfico dentro de la aldea, proceso que también estaría relacionado con el establecimiento del sitio Las Cuevas V.

Con relación a esto último, Olivera (1991) observa un proceso de aumento ocupacional en los momentos más tardíos del sitio Casa Chávez Montículo, en Antofagasta de la Sierra (Catamarca), indicado por la presencia de nuevos montículos en los que sólo aparece representado el componente superior, y relacionado con la mayor presencia de cerámicas de los valles mesotermales. Este proceso de crecimiento pudo haber ocurrido en Las Cuevas I y con posterioridad haber dado origen a Las Cuevas V, aunque por el momento se requiere de un mayor número de fechados que den sustento a esta explicación.

\section{Funcionalidad del sitio y de la Estructura 1}

El contexto recuperado en la Estructura 1 indica que esta se trataría de un recinto de actividades múltiples, en donde las áreas de descarte y combustión aparecen claramente segregadas hacia su interior.

El conjunto cerámico enseña un marcado predominio del grupo de cerámicas No Ordinarias sobre las Ordinarias, tendencia que también se registra en otros contextos formativos tempranos (De Feo 2010). Ello no implica que las piezas no pudieran cumplir funciones de tipo utilitarias, como el servicio, la preparación o el almacenamiento de líquidos o alimentos. En efecto, los atributos morfológicos y las dimensiones de las piezas permiten asociarlas con determinados usos primarios que se relacionan con actividades domésticas.

La jarra calceiforme debió emplearse en tareas de cocción dado que presenta abundantes rastros de hollín en su superficie y fue hallada junto a uno de los fogones secundarios. Asimismo, su contorno de simetría dorsiventral y su cuello largo permitirían relacionarla con el calentamiento de líquidos, mientras que la jarra más pequeña pudo haber sido usada para servir líquidos. Por su parte, los cuencos son aptos para el servicio de alimentos. Aquí es necesario señalar que los cuencos 1 y 9 , se hallaron asociados espacialmente con elementos óseos de camélidos. El diámetro de la boca de los cuencos, a excepción de los cuencos 3 y 10, se halla en el rango de tamaño considerado como vajilla de servicio de porciones individuales (Costin y Earle 1989 citado en Bugliani 2006).

La arcilla y los pigmentos -materias indispensables para confección de cerámica- cuyo color y composición es semejante a los que se observaron en las vasijas y los fragmentos, sugieren la manufactura de alfarería en el recinto. La presencia de instrumental de de piedra pulida 
indica el procesamiento de alimentos por molienda y machacado.

El conjunto lítico también permite extraer algunas conclusiones respecto de las actividades desarrolladas en la estructura analizada. Los porcentajes similares observados en desechos e instrumentos para la misma materia prima; así como los tamaños predominantemente pequeño y mediano-pequeño, el elevado índice de desechos fracturados y la baja presencia de corteza, indican que allí se habría llevado a cabo mayormente la formatización de instrumentos de obsidiana y basalto.

El cuarzo por su parte, se halla limitado exclusivamente a pequeños bloques reunidos en un sector de la estructura, cercano al muro interno. Esta materia prima no parece estar vinculada a la talla lítica dada su baja calidad, por el contrario, el tamaño regular de los bloques y su disposición agrupada sugiere que pudieron cumplir alguna función vinculada con el ritual y la señalización de espacios, tal como se observa en otros contextos contemporáneos o más tardíos del área (De Feo 2010; Meninato 2008).

La evidencia en conjunto señala un contexto doméstico, donde se habrían desarrollado diversas actividades, tales como el procesamiento, almacenamiento y servicio de líquidos y alimentos, la manufactura de instrumental lítico y posiblemente cerámico.

Esta funcionalidad se ve respaldada por las características constructivas de la estructura. Se ha observado por ejemplo, una marcada homogeneidad en las técnicas y materias primas utilizadas en los diversos sitios documentados para el Formativo. En todos los casos la materia prima es la piedra, mayormente esquistos, ignimbritas y basaltos, las cuales suelen ser muy regulares en su forma y tamaño. La técnica constructiva es predominantemente la pirca doble, formada por piedras colocadas con su eje mayor vertical y rellena con tierra y ripio. Se ha constatado asimismo, que otras unidades arquitectónicas semejantes en cuanto a su morfología y tecnología constructiva que han sido excavadas en sitios contemporáneos como Cerro El Dique y Las Cuevas I funcionaron también como espacios donde se concentró la vida doméstica de las comunidades aldeanas tempranas (Raffino 1977).

Ampliando nuestra escala de análisis de la estructura al sitio, también es posible realizar algunos comentarios respecto de su funcionalidad. El conjunto de información presentada permite la asignación del sitio Las Cuevas $\checkmark$ dentro de la categoría residencial (De Feo 2010) o "aldea" en términos de Raffino (1977), cuyo patrón de instalación se define por la presencia de un conjunto de estructuras domésticas dispuestas de forma diseminada en el terreno, acompañadas de otras mayores de formas cuadrangulares, las cuales estimamos se vinculan con el desarrollo de actividades pastoriles más que agrícolas dada la ausencia de cursos de agua y la baja productividad de los suelos, todas ellas emplazadas algunas cotas por sobre los fondos de valle aptos para el desarrollo de prácticas económicas de tipo extensivo.

\section{Organización y uso del espacio}

La excavación de la Estructura 1 permitió definir con mayor precisión algunas características constructivas de este tipo de recintos, entre ellas las techumbres, las cuales son de relevancia para establecer la manera en que se desarrollaron las actividades hacia el interior de estos espacios construidos. En trabajos anteriores sólo se mencionaba la existencia de huellas de horcones y restos de paja y barro entremezclados en el sedimento de estructuras circulares no mayores a los $4 \mathrm{~m}$ de diámetro de sitios como Las Cuevas I y Cerro El Dique (Cigliano et al 1976; Raffino 1977). Sobre esta base se infirió que las techumbres sólo estuvieron presentes en recintos medianos destinados a funciones habitacionales, mientras que aquellas circulares mayores, interpretadas como patios habrían carecido de ellas, dadas además su grandes dimensiones y la dificultad de cerramiento. No obstante, la presencia de postes en grandes recintos como el excavado en Las Cuevas V contradice esta afirmación. La posibilidad de cerrar estas estructuras tiene consecuencias sobre el patrón tradicionalmente denominado como "margarita" o Cerro El Dique-Tafí (Raffino 1988), mediante el cual articularon los espacios de actividades múltiples o patios y las habitaciones. Las techumbres en grandes estructuras convierten en prescindibles los recintos adjuntos menores, tradicionalmente interpretados como áreas de descanso y almacenaje.

En el caso de la Estructura 1 la evidencia parece indicar que estos espacios se desplazan hacia el interior del recinto o patio mayor, tal como se infiere de la subdivisión interna y la baja presencia de material recuperado en el área intramuros (fragmentos cerámicos $n=1$; desechos líticos $n=5$ y óseos $n=2$ ). Estructuras circulares de grandes diámetros, como la excavada en Las Cuevas $V$, parecen haber servido tanto como área de actividades múltiples como de habitación. Sin embargo, la organización de estructuras menores en torno a un recinto central también está presente en el sitio como puede observarse en el plano, aunque por el momento no han sido excavadas.

Enfocando nuestro análisis desde una escala más amplia se observa, como ya adelantáramos en párrafos anteriores, que la manera en que se organiza y se hace uso del espacio dentro del asentamiento responde al patrón propio de las instalaciones residenciales. Patrón predominantemente conformado por estructuras de planta circular, correlato de la unidad doméstica, diseminados en el terreno, y que en algunos casos, como ocurre en Las Cuevas V, se presentan acompañadas de otras de planta cuadrangular, aunque mucho menos 
frecuentes. Estas estructuras se disponen en el terreno con relativa independencia, sin elementos arquitectónicos que permitan vincularlas entre sí. Su crecimiento también parece haberse dado de forma aislada, no planificada, en función de la ausencia de regularidad en las distancias que las separan, la falta de elementos arquitectónicos que las articulen y las variaciones en los tamaños de las plantas. En términos generales los sitios residenciales abarcan grandes espacios abiertos, en los que están inmersas las estructuras domésticas y productivas, las cuales se hallan alejadas entre sí en distinto grado, pero siempre reflejando cierta autonomía. La única variante a esta regla la constituye Las Cuevas I, que tiene un patrón de crecimiento de tipo monticular, resultado de la superposición de elementos arquitectónicos.

Un hecho que hasta ahora no había sido destacado en la bibliografía es la disposición enfrentada, fondo de valle mediante, que se observa entre algunos asentamientos tempranos del área. Esta condición se verifica entre los sitios Cerro El Dique y Potrero Grande, los cuales se hallan distanciados 1 kilómetro, separados por los suelos fértiles de fondo de cuenca. Ahora también ha sido registrada entre los asentamientos de Las Cuevas I y V, ubicados cada uno sobre márgenes opuestas del río, separados por unos $500 \mathrm{~m}$.

Esta disposición pensamos pudo ser el resultado de la dinámica de crecimiento, a partir de la cual el desprendimiento de nuevas familias habría dado origen a otros sitios como sugirió anteriormente Raffino (1977). La instalación más moderna, en este caso Las Cuevas $V$ según lo indican los fechados disponibles y el material cerámico de superficie y excavación, no parece estar relacionada directamente con el acceso y control directo de nuevos territorios productivos, ya que las áreas de mayor productividad próximas a cada sitio son prácticamente las mismas dada su cercanía. Esta disposición enfrentada posiblemente pueda explicarse en función de la búsqueda de áreas más alejadas para las nuevas instalaciones, cuyo fin habría sido preservar los sectores de mayor productividad, más cercanos a los sitios, para el desarrollo de actividades económicas como la agricultura y el pastoreo. De allí que Las Cuevas $\checkmark$ se halle sobre la terraza, levemente más lejos del fondo de valle en comparación a Las Cuevas I, como mencionáramos anteriormente.

Existen otras evidencias que también aportan al conocimiento de la manera en que se fueron articulando los espacios, en este caso, el espacio regional y macrorregional, en la vida de las comunidades aldeanas formativas, y que asimismo, ponen de manifiesto fuertes interacciones entre ellas. Se trata de bienes de uso y consumo de procedencia foránea. Existen evidencias del consumo de aves propias de ambientes lagunares (Anatidae indet.) en el sitio Las Cuevas V, las cuales hasta hace no mucho tiempo sólo habían sido documentadas en sitios cercanos a tales ambientes, como Cerro El Dique y Potrero Grande (Raffino et al. 1977). Hábitats propicios para el desarrollo de estos recursos se hallan a una distancia mayor a los $45 \mathrm{~km}$ de Las Cuevas $\mathrm{V}$, en las lagunas del Toro o en cuencas endorreicas ubicada en quebradas altas del Nevado de Acay, localizadas a un trecho similar, lo cual señala una gran movilidad e interacción entre microambientes.

Si bien las interacciones con ámbitos aledaños habían sido destacadas en el pasado, su existencia se sustentaba básicamente en indicadores de uso y circulación restringida, como bienes suntuarios. Los resultados obtenidos de los análisis tecnomorfológico y físicoquímico de obsidianas son de suma importancia dado que destacan la dimensión utilitaria de estos intercambios macroregionales. En este sentido, estos resultados están señalando una fuerte dependencia de materias primas alóctonas, hecho que se desprende de la alta representación que adquiere la obsidiana dentro de los conjuntos líticos. También es indicador de la importancia que debió adquirir dentro de los sistemas económicos y de la subsistencia de las comunidades formativas.

El panorama que hasta aquí hemos delineado a la luz de nuevos datos se presenta por demás complejo. La verificación reiterada del patrón dual, como aldeas apareadas, que también se observa en algunos sitios del Formativo Tardío (De Feo 2010), sumada a las fuertes evidencias de interacciones con otros microambientes y regiones aledañas, va desdibujando el escenario tradicionalmente construido, de pequeñas aldeas de vida política y económica relativamente autónoma e independiente.

La Plata, 30 de mayo de 2011

\section{Agradecimientos}

A la comunidad de Las Cuevas por recibirme siempre con sus puertas y corazones abiertos. A las Dras. Aylen Capparelli y Verónica Lema por la determinación de los restos arqueobotánicos. A Ma. Celina Álvarez Soncini, Giovanna Salazar Siciliano, Lorena Ferrauiolo, Fernada Day, María Pérez e Ignacio Liggera por su colaboración durante los trabajos de gabinete. A todos aquellos estudiantes y graduados que participaron en los trabajos de campo llevados a cabo en el sitio, en especial a la Lic. Guillermina Couso. A Diego Gobbo por su colaboración en la confección de algunas figuras. A los evaluadores anónimos cuyos comentarios enriquecieron sustancialmente el manuscrito original. Estas investigaciones han sido financiadas gracias a una Beca Doctoral otorgada por el CONICET.

\section{Bibliografía}

Álvarez Soncini, M. C. y M. E. De Feo. 2010. Obsidianas 
en contextos tempranos de la Quebrada del Toro: Análisis tecno-morfológico e identificación de fuentes de aprovisionamiento en los sitios Las Cuevas I y V. En Actas del XVII Congreso Nacional de Arqueología Argentina, Tomo I, pp. 19-24. Mendoza.

Borrero, L. A. 1990. Fuego-Patagonian Bones Assemblages and the Problem of Communal Guanaco Hunting. En Hunters of the Recent Past, editado por L.B. Davies y B.O.K. Reeves, pp. 373-399. Unwin Hyman, London.

Bugliani, M.F. 2006. Consumo y representación en el Formativo del sur de Valles Calchaquíes. Tesis Doctoral en Ciencias Naturales, Facultad de Ciencias Naturales y Museo, Universidad de La Plata. Ms.

Caparelli, A. y R. Raffino. 1997. La etnobotánica de El Shincal (Catamarca) y su importancia para la arqueología I: Recursos combustibles y madereros. Parodiana 10:181188.

Cigliano, E., R. Raffino y H. Calandra. 1976. La aldea Formativa de Las Cuevas (Provincia de Salta). Relaciones de la Sociedad Argentina de Antropología. N.S. Vol. X: 73-130.

De Feo, M. E. 2010. Organización y uso del espacio durante el Período Formativo en la Quebrada del Toro (Pcia. de Salta). Tesis Doctoral en Ciencias Naturales, Facultad de Ciencias Naturales y Museo, Universidad de La Plata. Ms.

De Nigris, M. y G. Mengoli Goñalons. 2004. El guanaco como fuente de carne y grasas en Patagonia. En Contra viento y marea. Arqueología de Patagonia, editado por T. Civalero, P. Fernández y A. Guráieb, pp. 537544. Instituto Nacional de Antropología y Pensamiento Latinoamericano, Buenos Aires.

Dougerthy, B. 1974. Análisis de la variación medioambiental en la subregión arqueológica de San Francisco (Región de las Selvas Occidentales- Subárea del Noroeste Argentino). Etnía 20:1-11.

Elkin, D. 1995. Volume Density of South American camelid skeletal parts. International Journal of Osteoarchaeology 5: 29-37.

Heredia, O., J.A. Pérez Gollán y A.R. González. 1974. Antigüedades de la cerámica polícroma en el Noroeste argentino. Revista del Instituto de Antropología 5: 73132.

Izeta, A. 2004. Zooarqueología del Sur de los valles Calchaquíes. Estudio de conjuntos faunísticos del Período Formativo. Tesis Doctoral inédita, Facultad de Ciencias
Naturales y Museo, Universidad de La Plata. Ms.

Krapovickas, P. 1955. El yacimiento de Tebenquiche (Puna de Atacama). Publicaciones del Instituto de Arqueología 3. Universidad de Buenos Aires.

Meninato, I. 2008. El arte rupestre de Tastil. Estudio reinterpretativo. Tesis de Licenciatura en Antropología, Facultad de Humanidades, Universidad Nacional de Salta. Ms.

Munizaga, C. 1963. Tipos Cerámicos del sitio Coyo en la Región de San Pedro de Atacama. Congreso Internacional de Arqueología de San Pedro de Atacama, 2. Anales de la Universidad del Norte: 99-130.

Olivera, D. 1991. Tecnologías y Estrategias de Adaptación en el Formativo (Agroalfarero Temprano) de la Puna meridional Argentina. Un caso de estudio: Antofagasta de la Sierra (Pcia. De Catamarca R.A.). Tesis Doctoral en Ciencias Naturales, Facultad de Ciencias Naturales y Museo, Universidad de La Plata. Ms.

Raffino, R. 1977. Las aldeas del Formativo inferior en la Quebrada del Toro, (Pcia. de Salta. Argentina). Obra del Centenario del Museo de La Plata, II: 253-299.

Raffino, R. 1988. Poblaciones indígenas en Argentina. Urbanismo y proceso social precolombino. Ed. TEA, Buenos Aires.

Raffino, R y J. Togo. 1970. El yacimiento arqueológico de Cerro El Dique. Quebrada del Toro. Nota Preliminar. Revista Itá Aripí 1: 5-9.

Raffino, R, E. Tonni y A. Cione. 1977. Recursos alimentarios y economía en la Región de la Quebrada del Toro, Provincia de Salta, Argentina. Relaciones de la Sociedad Argentina de Antropología. Vol. XI: 9-30.

Stuiver, M. y P. Reimer. 1986. A computer program for radiocarbon age calibration, Radiocarbon 28:1022-1030.

Tarragó, M. 1980. Los asentamientos aldeanos tempranos en el sector septentrional del valle Calchaquí y el desarrollo agrícola posterior. Estudios Arqueológicos 5:29-53.

Todd, L. 1987. Taphonomy of the Homer II Bonebed. En The Homer Site: The Type site of de Cody Cultural Complex, editado por G. Frison y L. Todd, pp. 107-198. Academy Press, Orlando.

Vivante, A y N. Palma. 1966. Habitaciones pozo y semipozo con paredes de guano en la puna argentina. Revista del Museo de La Plata (NS) Sección de Antropología, Tomo VI: 17-43. 